\title{
Manipulation of p53 Protein in Bladder Cancer Treatment
}

\author{
Siti Farizan Mansor \\ Faculty of Health Sciences, Universiti Teknologi MARA, Cawangan Pulau Pinang, Pulau Pinang, Malaysia.
}

\begin{abstract}
Chemotherapy and radiotherapy are gold standard treatment for bladder cancer (BC) for over 50 years. The efficacy on early stage BC patients is virtuous. However, patients with aggressive cancer growth benefited less from the therapy. Aberrant p53 was found in more than $50 \%$ of high-grade BC patients. Therefore, targeting p53 in a subset of high-grade $\mathrm{BC}$ patients expressing aberrant $\mathrm{p} 53$ is a promising strategy. In this paper, p53 role in $\mathrm{BC}$ carcinogenesis is discussed. Followed by p53-targeting strategies in current BC treatment. Besides, p53-targeting strategies that have been implemented in other types of cancer and their potential to be adapted in $\mathrm{BC}$ will be deliberated. Although targeting p53 is promising, none of the strategies studied were successfully implemented in healthcare settings. Restoration of p53 as the guardian of the genome is an exciting area for translational research. It has potential to replace the genotoxic chemotherapy and radiotherapy, thus, eliminating the notorious painful sideeffects on a subset of high-grade BC patients. Searches were performed on PubMed and Google Scholar web using the keywords "bladder cancer" or "urothelial cancer" or "urothelial cell carcinoma" and "p53". Only full papers of research articles and review papers were included for analysis. Papers were categorized as either p53 function, current treatment using p53 and future potential treatment using p53 for details analysis.
\end{abstract}

KEYWORDS: bladder cancer, urothelial cell carcinoma, p53, gene therapy

\section{INTRODUCTION}

Bladder cancer $(\mathrm{BC})$ is the most expensive cancer to treat and manage. Transurethral resection of bladder tumour (TURBT) could only remove the tumour temporarily due to high recurrence rate. Hence patients need to repeat TURBT few months after the initial tumour removal though the cost of each TURBT procedure is not cheap. This condition has become a burden to the government and patients over many years. Thus, to reduce the recurrence rate, bacillus Calmette-Guerin (BCG), wh chemotherapy or radiotherapy are combined with hindered the normal p53 function in heterozygote TURBT procedure. Nonetheless, BCG raised immune mutation. ${ }^{1}$

response in only some patients, while chemotherapy and radiotherapy are associated with painful side effects.

\section{Corresponding Author:}

Dr. Siti Farizan Mansor

Faculty of Health Sciences,

Universiti Teknologi MARA, Cawangan Pulau Pinang, Kampus Bertam, 13200 Kepala Batas, Pulau Pinang, Malaysia.

Tel No : +604 562 3532;

E-mail : sfmansor@gmail.com
Chemotherapy and radiotherapy are gold standard for $\mathrm{BC}$ management. In high grade BC, these genotoxic therapies are less effective because most cases confer mutant p53 gene (mt-p53), thus unable to initiate p53induced apoptosis. Ideally, the nonfunctional p53 should be corrected first, then genotoxic therapies follows. Heterozygous p53 mutation comprised of both wildtype and mt-p53. The mt-p53 protein are overexpressed, while wild-type p53 are relatively underexpressed. This

The transactivation targets of $\mathrm{p} 53$ are best described through the p53 pathway. In inactive state, p53 is a complex-folded structure and constantly bound to its regulator protein, $\mathrm{Mdm} 2$. The sensing of DNA damage by Ataxia Telangiectasia Mutated (ATM) will trigger the p14ARF to perform post-transcriptional modification on $\mathrm{p} 53$. This will caused release of p53 off the Mdm2. ATM will then phosphorylate and unfold 
p53 to facilitate its binding to DNA. This is important as the p53 acts as transcription factor for genes involved in DNA damage response mechanism.

p53 is the transcription factor for essential genes in DNA damage response (DDR) such as CDK inhibitor p21, growth arrest and DNA damage 45 (GADD45), and BAX. Upon activation, p53 will initiate the expression of p21 and GADD45 gene that will act in arresting the cell cycle, and repairing the damaged DNA, respectively. If the damage is beyond repair, p53 will activate BAX gene transcription, on which its protein will later bind to apoptosis-inhibiting protein BCL-2. Thus, apoptosis is initiated (Figure 1).,.$^{2,3}$

This paper discussed p53 role in BC carcinogenesis and p53-targeting strategies in current BC treatment. Besides, p53-targeting strategies that have been implemented in other type of cancer and their potential to be adapted in $\mathrm{BC}$ is deliberated.

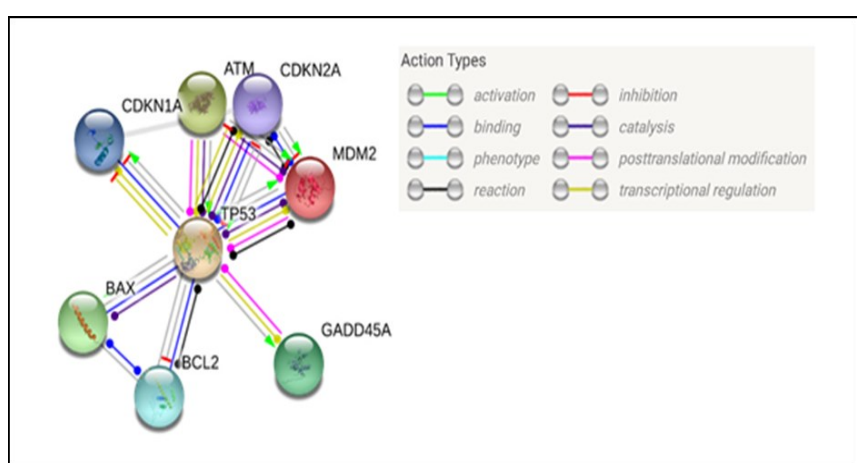

Figure 1: p53 pathway initiated by DNA damage response mechanism. Network pathway can be viewed in details at https:// string-db.org/cgi/network.pl?taskId=0tAWpxj0Uouf

\section{Role of p53 in Bladder Cancer}

Fifty percent of cancer cases acquire a mechanism to inactivate p53 function to bypass apoptosis. ${ }^{4}$ DNA damage is sensed by ATM, but DDR could not be activated. Cancerous cells continue to proliferate, eventually lead to mutation accumulation and genome instability (Figure 2).

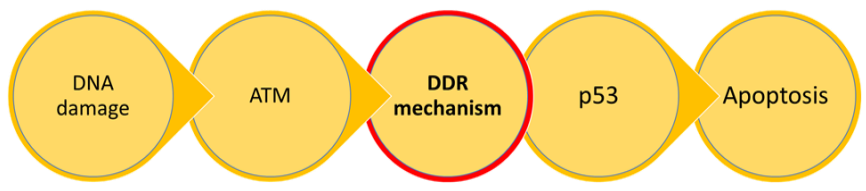

Figure 2: DNA damage response is triggered by ATM. DDR will then activates $\mathrm{p} 53$, followed by transcriptional activation of downstream genes which will prompt apoptosis.
$60 \%$ of BC cases confer mutp53 at exon 5-11. mutp53 is commonly associated with mutRb gene in high grade, invasive and poor prognosis BC. 5,6 Whereas, mutation in either p53 or RB gene, causes unregulated proliferation but less aggressive compared to BC with both mutations, which claimed to have the worse prognosis. ${ }^{7}$

$20 \%$ of all BC cases were caused by p53 gene mutation at exon 1-4 which accompanied with mutCDKN2a and ARF loss of function (Figure 3). Therefore, it was suggested that p53 mutation may be followed by mutation in RB, CDKN2a and ARF gene.5,6 However, this could not be validated experimentally because when $\mathrm{RB}$ and p53 gene were knocked out in mice, they suffered early death due to haematopoietic problem, neurological disorder, lymphomas and sarcomas, while the urothelial cells still intact. ${ }^{8}$ Although many literatures claimed both $\mathrm{RB}$ and $\mathrm{p} 53$ mutation are culprits promoting progression of UCC, both mutations were also found incapable to initiate UCC in early stages. ${ }^{8}$ The culprit initiating ow grade and non-invasive UCC is the RAS oncogene, while RB and p53 mutation only work later, in order to worsen the chaos. ${ }^{8}$

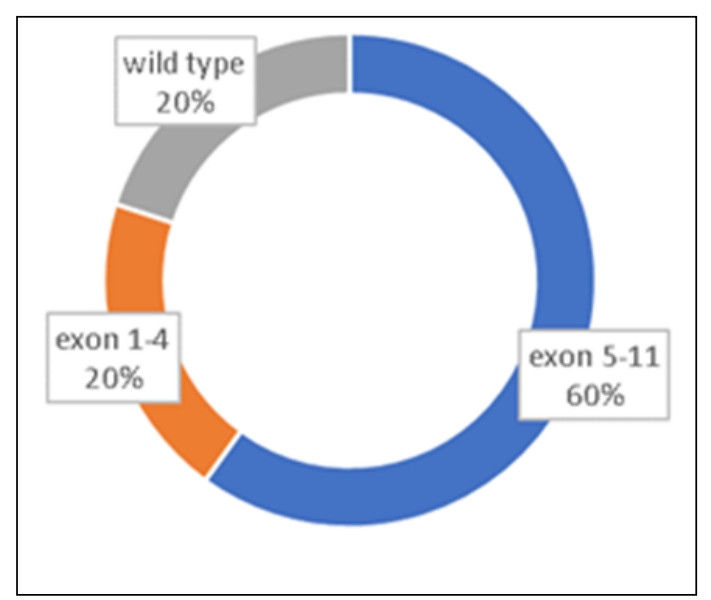

Figure 3: $60 \%$ of all bladder cancer cases confer p53 mutation at exon $5-11,20 \%$ mutation at exon $1-4$ and remaining $20 \%$ confer wild-type p53.

p53 loss of heterozygosity caused overexpression of mtp53 protein. Mt-p53 is associated with high-grade and invasive UCC with low survival rate and putative UCC prognostic marker. ${ }^{6,7}$ T2 UCC with overexpressed p53 has higher recurrence rate $(80 \%)$ compared to $\mathrm{T} 1$ $(62 \%){ }^{7}$ 
Mt-p53 protein structure nullified its interaction with the regulator, $\mathrm{Mdm} 2$ via 3 ways. First, mt-p53 protein inhibits transcriptional activation of $\mathrm{Mdm} 2$ gene. Second, it disabled p53 ubiquitination by Mdm2. Third, mt-p53 protein structure has disabled its binding to $\mathrm{Mdm} 2$, thus halting transportation of p53 to cytoplasm. Thus, mt-p53 is accumulated in nucleus and cannot be degraded by proteasome (Figure 4). ${ }^{4}$

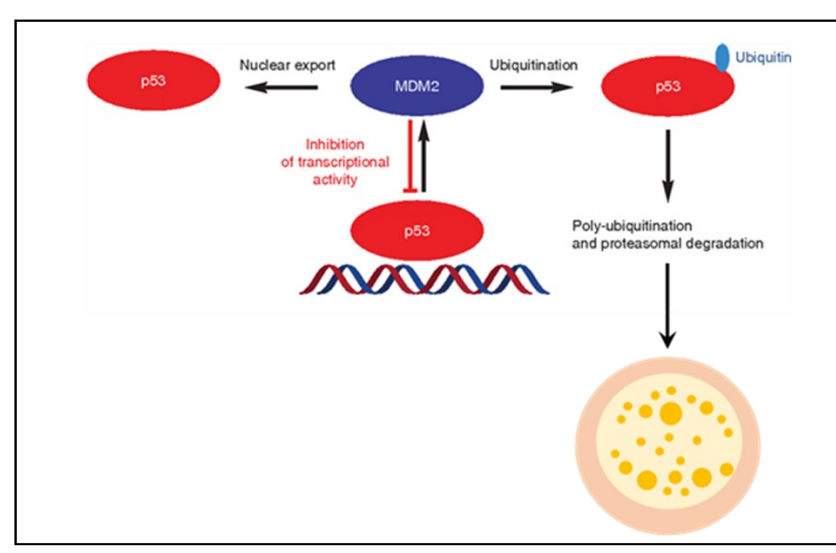

Figure 4: Wild-type p53 acts as a transcription factor for $\mathrm{Mdm} 2$, thus activating downstream genes to activate tumour suppression. However, aberrant p53 can no longer activates tumour suppression and accumulates in the nucleus.

As a response to DDR mechanism, p53 will transactivates p21 which will induce cell cycle arrest. ${ }^{4}$ However, Mitra suggested that p21 could be activated independently without p53 transactivation. ${ }^{7}$ Apparently, p53 mutation with wild-type p21 is associated with lower recurrence rate. Expression of wild-type p21 was suggested to render the effect of p53 mutation. In contrast, p21 loss of function derived from p53 mutation is associated with high recurrence rate. $6,7 \mathrm{p} 21$ and p53 status may serve as a prognostic tool for UCC, as long as the tumour has not spread to lymph node. ${ }^{7}$

$\mathrm{Mdm} 2$ regulates $\mathrm{p} 53$. When $\mathrm{p} 53$ has done its job or no longer needed, $\mathrm{Mdm} 2$ binds to it, initiates its ubiquitination followed by transportation to cytoplasm for degradation by proteasome. ${ }^{2} \mathrm{Mdm} 2$ expression was found to be increasing proportionally with the increasing grade of UCC.7 Interestingly, there are cases where inhibited p53 function found in BC patients with wild-tye $\mathrm{p} 53$. The inhibited function is caused by overexpression of $\mathrm{Mdm} 2$ and its associate, Mdm4 which initiates p53 proteasomal degradation. ${ }^{9}$ Thus, aberrant p53 is caused by a wide spectrum of mutations, on which they can be manipulated and served as potential targets for p53-based BC therapy.

\section{Role of p53 in Current Bladder Cancer Treatment}

Chemotherapy usually combines few regiments that target cells at different stages of proliferation for maximal efficacy. Some destroy cells during cytokinesis, others target the newly synthesized DNA during chromosome duplication. Regiments that are commonly prescribed for metastatic BC are methotrexate, vinblastine, adriamycin and cisplatin (MVAC) with 2year survival rate of up to $20 \%$. Gemcitabine and cisplatin are more preferred due to their lower toxicity risk compared to MVAC. ${ }^{11}$

Radiotherapy utilizes shots of ionizing waves onto specific cancer cell areas with minimal damage to surrounding normal tissue. In BC management, radiotherapy is performed post-TURBT to kill the remaining cancer cells. Five-year survival rate for patients who underwent radiotherapy post-TURBT was doubled compared to radiotherapy only. Radiotherapy post-TURBT and chemotherapy are commonly prescribed for BC stage T2. However, there is still no specific guideline on BC management and treatment. Treatments are indeed dependent on the respective urologists evaluation. ${ }^{12}$

While chemotherapy and radiotherapy are gold standard in BC management, the efficacy of these 2 regiments is minimal. No one having these treatments has known to be cured from BC. There are barriers blocking the treatments from activating p53-induced apoptosis. One of the greatest concerns recently is the involvement of nuclear factor $\mathrm{kB}(\mathrm{NF}-\mathrm{kB})$ on p53-induced apoptosis.

In normal individual, NF-kB was found to be activated during immunity and inflammatory response. Besides the tumour suppressor function, it also promotes cancer development. For the latter, it acts in 2 mechanisms; enhancing tumour cells proliferation and suppressing p53-induced apoptosis. ${ }^{13}$ NF-kB was found to downregulate PTEN expression; the TSG that suppressed cell survival through PI3K/Akt pathway. NF $-\mathrm{kB}$ also involves in the activation of rat sarcoma (RAS) in MAPK pathway which leads to constitutive growth and survival of cancer cells. ${ }^{13,14}$ 
On the other hand, PTEN abrogation was found to play a role in suppression of p53-induced apoptosis through the activation of $\mathrm{NF}-\mathrm{kB}$ transcription factor on various types of apoptosis inhibitor molecules. ${ }^{15,16}$ NF-kB stimulate the expression of FLICE-like inhibitory protein (FLIP), a molecule that possess high similarity of homology to caspase- 8 but without the protease property. FLIP competes with caspase- 8 for forming complex with death-inducing signaling complex (DISC), thus blocking caspase-8 and downstream effector caspases to perform apoptosis. ${ }^{13,17}$ Other molecules being overexpressed via $\mathrm{NF}-\mathrm{kB}$ transcription factor are inhibitor of apoptosis (IAP) as well as the antiapoptotic member of bcl-2 family, whereby both in turns inhibit effector caspases and the proapoptotic members of bcl2 family, respectively. ${ }^{13,18}$

$\mathrm{NF}-\mathrm{kB}$ transcription factor is essential in activating production of immunoglobulins and other proinflammatory molecules. Although NF-kB inhibition may restore the function of proapoptosis members of bcl-2 family, we could not simply resort to that option because it will jeopardize one's immunity. Thus, scientists are now trying to find possible downstream molecule in NF-kB pathway that could be silenced, without having to risk the patients' immunity. ${ }^{13,14}$

Correlation of p53 status and response to treatment is controversial and debatable. Most literatures suggested that patients with mutation in p53 were found to be less responsive to chemotherapy and radiotherapy. Wu and colleagues had tested responsiveness of radiotherapy prior to cystectomy procedure on muscle invasive- BC patients confer either wild-type p53 or mt-p53. Patients confer wild-type p53 produced higher survival rate and lower risk to metastasize compared to those confer mtp53. ${ }^{19}$ However, this study was contradictory to other studies on muscle invasive - BC which stated that p53 status has no association with survival rate and response to genotoxic therapies. ${ }^{20,21}$

Furthermore, Slaton and his team had reported that BC patients with mt-p53 responded poorly to chemotherapy because mutation at the DNA-binding domain blocked the mutated protein from binding to downstream responsive genes involved in apoptosis. ${ }^{22}$ This however had contradicted the earlier experiment by Cote, who claimed that invasive $\mathrm{BC}$ patients with wild-type p53 showed minimal response to adjuvant chemotherapy compared to those with the mt-p53, which showed encouraging response with low recurrence rate and high survival rate. ${ }^{23}$ This has been partially supported by Zamble who concluded that the mt-p53 only responded to drug that induce DNA damage by nucleotide excision such as cisplatin. ${ }^{24}$

On the other hand, most tumours in premalignant stage are found to be sensitive to genotoxic therapies and able to activate apoptosis because mutation of $\mathrm{p} 53$ or $\mathrm{LOH}$ only developed at the later stage of cancer. ${ }^{25,26}$ In contrast, most malignant tumour possessed resistance towards genotoxic agents because p53 mutate at this stage and the tumour, especially the solid ones, are getting used to various non-genotoxic stresses such as hypoxia and limitation of growth factor supply, thus made them adapted and resisted apoptosis. ${ }^{25}$ This issue will continue to be debated and on-going research for deeper elucidation of the p53 correlation on genotoxic therapies and p53-induced based therapy are underway.

\section{Potential Strategies for Bladder Cancer Therapy Targeting p53}

Chemotherapy and radiotherapy activate p53 inducedapoptosis by damaging cancerous cells' DNA. However, patients with mt-p53 poorly-respond to these treatments. Most high stage $\mathrm{BC}$ patients are overexpressing mt-p53 protein. Thus, DNA damage is sensed by ATM, but mt-p53 fails to perform transactivation of pro-apoptotic downstream genes. ${ }^{27}$ p53 function can be restored by various means; wildtype p53 gene delivery by virus, p53 peptide delivery by non-viral methods, and the manipulation of p53 regulators.

\section{p53 Gene Therapy using Viruses}

p53 gene therapy in $\mathrm{BC}$ cell lines a few days prior to cisplatin treatment was found to significantly increase chemosensitivity. ${ }^{28,29}$ Furthermore, synergistic effect of p53-gene therapy with radiotherapy was also seen in other type of cancers. .0,31 $^{3}$ 
Wild-type p53 gene is administered through various vectors such as adenoviral, retroviral, lentiviral and liposome. Adenoviral vector gain most concern and regarded as the best wild-type p53 transporter. ${ }^{32}$ A good transporter is able to specifically target cancer cells without messing surrounding normal cells.32 Besides, adenovirus possess additional features such as high expression of transgene, capability to transfect various type of human tissues, low risk of xenograft and a wellestablished safety procedure. ${ }^{32}$

Trials of p53 gene therapy are performed through 2 approaches; intratumoural injection and intravesical instillation. Intratumoural injection involved injection of vectors directly to the tumour area. Whereas, intravesical instillation delivers vectors into bladder cavity via catheterization. Catheter is sealed temporarily for optimal vector exposure to bladder wall. Patients are asked to turned around in several positions to ensure homogenous vector distribution, followed by irrigation with saline. ${ }^{33}$

Kuball and his colleagues tested the efficacy of both approaches. Prior to cystectomy, adenoviral-p53 vector were administered in BC patients via either intratumoural injection or intravesical instillation. The transduction enhancing agent, CHAP is used in intravesical instillation, but not in intratumoural injection. Level of p53 transactivation target genes such as $\mathrm{p} 21, \mathrm{Bax}$ and $\mathrm{bcl}-2$ gene were analysed on cystectectomy biopsies. Intravesical instillation with CHAP was significantly more effective compared to direct intratumoural injection. ${ }^{32,33}$

p53 gene delivery through intratumoural injection was found to produce encouraging result during phase 1 clinical trial on non-small cell lung cancer (NSCLC), head and neck cancer, ovarian cancer and liver cancer. However, it was found to be not significant during phase 2 clinical trial on NSCLC due to insufficient transgene delivery and transduction. ${ }^{34,35}$ This suggested that intratumoural injection works better in solid tumours compared to cancer of cavity organs. Intravesical instillation was found to be more effective because it allows better vector exposure to tumour cells and homogenous distribution in bladder cavity. ${ }^{33}$ Adenoviral vector is considered safe in which it produces minor side effects such as fatigue, minor burning sensation of urethra and bladder. This could be relief by reducing the instillation duration. ${ }^{33,36,37}$

p53 gene therapy experiences several failed clinical trials and it is still far from 100\% efficacy. There are barriers that blocked gene therapy efficacy. Firstly, the coxsackie and adenoviral receptor (CAR) on cancer cells' surface, which assists the attachment and penetration of adenoviral vector into BC cells through endocytosis, is harboring varying amount of expression between individuals and even within the same tumour of different region. ${ }^{32,36}$ What makes it worse is that the CAR expression was found to be low or null in high grade BC. 38 To overcome this, CAR cDNA sequence is added in adenoviral-p53 vector. This increased CAR expression on cancer cells, thus promote vector uptake. 39,40

Glycosaminoglycan layer (GAG) is essential in protecting urothelial layer from infection. However, GAG is blocking vector from binding to CAR. ${ }^{36}$ This problem can be overcome by supplementing gene therapy with molecules that could break open the layer and drive the vector across GAG straight into the target site; such as CHAP, detergent dodecyl maltoside (DDM) and polyamide Syn-3. Nevertheless, efficacy and safety of these molecules are still being studied. 40,41

\section{p53 Peptide Delivery to Bladder Cancer Cells using Non-viral Methods}

The efficacy of p53 gene therapy via viral delivery is better in non-invasive $\mathrm{BC}$ compared to invasive counterpart. Major drawback of this method is that it could not be administered systemically, thus less applicable to invasive and metastasized BC. Better approach to treat invasive and metastasized $\mathrm{BC}$ is through p53 peptide delivery via membrane-permeable peptide vectors. It is a new approach for p53-based BC therapy which expected to tackle the invasive and metastasis problem. ${ }^{42}$

There are few types of vectors that have been used in p53 peptide delivery, namely; cell penetrating peptide (CPP), protein transduction domain (PTD) and short peptide vector. They are composed of less than 12 
amino acid residues such as polyarginine, PTD of HIV Type 1 TAT protein and PTD of flock house virus. These vectors attached-p53 peptide were administered into target cells and successfully activated various downstream target genes of wild-type p53-transcription factor. ${ }^{43}$ Unlike gene therapy using viral method, these vectors are internalized into cells through lipid raftdependent macropinocytosis rather than endocytosis and specific receptor as in the CAR. ${ }^{43,44}$

p53 transcription factor composed of 3 domains; activation domain, sequence-specific DNA binding domain, and oligomerization domain. There are 2 sequence-specific DNA binding domains. The first DNA binding domain binds only to specific DNA sequence of the DDR genes such as p21 gene, GADD45 gene and Bax gene. The second DNA binding domain is less specific in which it binds to various DNA structures such as short single strands, irradiated DNA as well as DNA sequence having insertions or deletions. ${ }^{45}$

The non-specific DNA binding domain is composed of 30 amino acids which located at the residue number 363 to 393 towards the end of $\mathrm{C}$-terminal, thus this domain is also called p53 C-terminus. Whereas, the sequencespecific DNA binding domain is known as the core domain. The p53 C-terminus is associated with the capability of core domain to bind to its cognate region. In other words, p53 C-terminus served as regulator of the core domain which function to activate the latent p53. In response to DDR, p53 C-terminus is subjected to conformational modification via acetylation and phosphorylation, which activates the core domain to bind to its cognate region, thus activates p53 protein. ${ }^{45,46}$ Unfortunately, this vital regulatory domain was found to be not functional in most of invasive BC cases. ${ }^{43}$

p53 C-terminus delivery has potential to be manipulated for BC treatment. Researchers incorporated p53 Cterminus with 11 poyarginine vector (11R-p53C') which successfully got itself into plasma membrane of cancer cells and halting the proliferation of BC cells and oral cancer cells. ${ }^{48}$ Although this method possessed less toxicity compared to p53 gene therapy via adenoviral, the $\mathrm{BC}$ cells need high and frequent dosage of $11 \mathrm{R}$ p53C'to counteract rapid degradation of the molecule by ubiquitination. Besides, some of them were entrapped in macropinosome which hindered them to be fused into the target region. ${ }^{44,48}$

However, recent research on haemagglutinin-2 protein had shed light that may lead us to solution of this problem. This NH2-terminal 20 amino acid peptide of the influenza virus haemagglutinin-2 protein (HA-2) with its $\mathrm{pH}$-based fusogenicity got the entrapped 11Rp53 to be released from macropinosome so that the molecule could swim right through towards the target region, and got fused with the mt-p53 C-terminus at $\mathrm{pH}$ 5 , thus turning on the latent $\mathrm{p} 53$ protein to action. ${ }^{43,49-51}$

\section{Manipulation of p53 Regulators}

$\mathrm{Mdm} 2$ and $\mathrm{Mdm} 4$ are negative regulators of p53 of which high expression was found during embryogenesis. They prevent p53 mediated-cell cycle arrest and apoptosis, thus promote proliferation and differentiation. There are 2 hypothesis on how Mdm2 and $\mathrm{Mdm} 4$ function as p53 regulators. The first hypothesis, Mdm 2 and $\mathrm{Mdm} 4$ inhibit p53 via 2 different pathways. Mdm2 directly drives ubiquitination of p53 for degradation by proteasome, whereas Mdm4 antagonizes the transcription of downstream genes such as p21, GADD45 and Bax during transactivation by p53 protein during the cell cycle checkpoints. Second hypothesis suggested simultaneous p53 inhibition by both Mdm2 and Mdm4. They pair to form heterodimer complex before approaching p53. The complex drives p53 for degradation by proteasome. ${ }^{52}$

Almost $50 \%$ of all cancer patients confer wild-type p53. Theoretically, this could perfectly initiate cell cycle arrest and apoptosis. However, this does not happened because the regulator, $\mathrm{Mdm} 2$ and $\mathrm{Mdm} 4$ were also highly expressed in most wt-p53 patients. ${ }^{52,53}$ Nonetheless, scientists are puzzled on how Mdm4 are overexpressed in tumour cells that possessed wild-type p53. Theoretically, Mdm4 is inversely correlated to p53. Gilkes suggested that Mdm4 gene expression is among one of the downstream targets of mitogenic signaling derived from oncogenes RAS and FGFR. ${ }^{44}$ On the other hand, Reimenschneider and his team claimed that in certain cancer, Mdm4 gene itself has turned into an oncogene, in which it is commonly mutated through 
gene amplification and SNPs. $.5,56$

Therefore, deleting $\mathrm{Mdm} 2$ and $\mathrm{Mdm} 4$ functions may restore $\mathrm{p} 53$ function and could promote suppression of tumour cells growth. Knockdown of Mdm4 expression resulted in increase apoptosis in mice lymphoma $a^{57-59}$ and breast cancer cell lines. ${ }^{60}$ However, the function and regulatory mechanism of $\mathrm{Mdm} 4$ needs to be further elucidated, so that other external factors which contribute to $\mathrm{Mdm} 4$ function can be carefully taken into consideration when targeting $\mathrm{Mdm} 4$ for knockdown. Inhibition of $\mathrm{Mdm} 4$ can be performed in 2 approaches; reduce $\mathrm{Mdm} 4$ expression and prevent the interaction of Mdm4-p53 as well as the formation of Mdm2-Mdm4 heterodimer complex. ${ }^{62,63}$

There are 3 ways to reduce $\mathrm{Mdm} 4$ expression. First method; since Mdm4 is one of the downstream targets of mitogenic signaling derived from oncogenes, blocking of mitogenic signaling pathway inhibits the transcriptional activation of $\mathrm{Mdm} 4$, thus prevent its expression. Second method; by applying a tiny molecule that could antagonize the transcription factor (TF) from binding to Mdm4 promoter, thus blocking Mdm4 transcription. Third method; development of small interference RNA (siRNA) that is capable to antagonize Mdm4 mRNA, thus blocking mRNA translation. ${ }^{53}$ It was reported that RNAi is promising. Nonetheless, successfulness of siRNA delivery into deep solid tumour mass requires further study. ${ }^{53}$

Formation of Mdm4-p53 and Mdm4-Mdm2 binding complex leads to p53 degradation. To prevent formation of both complexes, a synthetic compound that possessed higher affinity for Mdm4 compared to p53 and $\mathrm{Mdm} 2$ was developed. This omit p53 binding to Mdm 4, thus restore cancer suppression. ${ }^{3}$

Nutlin is a non-peptide synthetic compound that binds to $\mathrm{Mdm} 2$ specifically on the p53-binding site. Once nutlin occupied the p53-binding site on $\mathrm{Mdm} 2$, there is no room left for p53, thus Mdm2-p53 binding is inhibited. ${ }^{61-63} \mathrm{Mdm} 2$ and $\mathrm{Mdm} 4$ possessed similar peptide structure. However, nutlin failed to bind to Mdm4 on its p53-binding site. ${ }^{64,65}$

This failure lead to NMR study of structure and conformation of $\mathrm{Mdm} 2$ and $\mathrm{Mdm} 4$. Amino acid at the p53-binding site of Mdm2 and Mdm4 is different by 3 residues. Towards the end of the alpha helix domain, Mdm4 possessed proline, serine and proline at residue number 95, 96 and 97, respectively, in which the Mdm2 do not. ${ }^{53}$ This tiny difference caused incompatibility of Mdm4 to nutlin. In other study, p53-binding site of $\mathrm{Mdm} 2$ was relatively more accessible to nutlin than $\mathrm{p} 53-$ binding site of Mdm4. ${ }^{52,53}$

However, there is one success story of $\mathrm{Mdm} 4$ interaction with nutlin. When nutlin were given in high dosage, it was found to suppress the growth of retinoblastoma overexpressing $\mathrm{Mdm} 4.66$

Despite the mixed success of Mdm4 susceptibility to nutlin, there is a need to develop compound or peptide that could target both Mdm2 and Mdm4 simultaneously because they are both exclusively overexpressed in most tumours especially in wild-type p53 UCC patients. This has been brought close to reality by $\mathrm{Hu}$ and his colleagues. They developed adenoviral mediated-peptide that could tackle both Mdm2 and Mdm4.60,67 Though, scientists need to work harder on the delivery method of the peptide because adenoviral delivery covers a limited range of cancer types and none has been reported to be effective on $\mathrm{BC}$ cells. ${ }^{60}$

\section{CONCLUSION}

p53 gene delivery by viral vectors, p53 peptide delivery and manipulation of $\mathrm{p} 53$ regulators are strategies for p53 reactivation. Some results are promising for restoration of p53 function. Nonetheless, these strategies are still far from perfection. There are still barriers remained and many await to be discovered and elucidated. Restoration of p53 role is an exciting area for translational research. It has potential to replace the genotoxic chemotherapy and radiotherapy, thus, eliminating painful side effects on a subset of high-grade $\mathrm{BC}$ patients, provide better quality of life and reduce treatment cost for $\mathrm{BC}$ management.

\section{CONFLICT OF INTEREST}

The author declare that there is no conflict of interests regarding the publication of this manuscript. 


\section{REFERENCES}

1. Levine AJ, Finlay CA, Hinds PW. P53 is a tumour suppressor gene. Cell. 2004;116:S67-70.

2. Kumar V, Abbas AK, Fausto N, Aster JC. Robbins and Cotran pathologic basis of disease, professional edition e-book. elsevier health sciences; 2014 Aug 27.

3. Branzei D, Foiani M. Regulation of DNA repair throughout the cell cycle. Nature reviews Molecular cell biology. 2008;9(4):297.

4. Ray S. The Cell: A Molecular Approach. The Yale journal of biology and medicine; 2014.

5. Spiess PE, Czerniak B. Dual-track pathway of bladder carcinogenesis: practical implications. Archives of pathology \& laboratory medicine. 2006;130(6):844-52.

6. Knowles MA, Hurst CD. Molecular biology of bladder cancer: new insights into pathogenesis and clinical diversity. Nature Reviews Cancer. 2015;15 (1):25.

7. Mitra AP, Hansel DE, Cote RJ. Prognostic value of cell-cycle regulation biomarkers in bladder cancer. In Seminars in oncology. 2012; 39(5):524-533.

8. Ye F, Wang L, Castillo-Martin M, McBride R, Galsky MD, et al. Biomarkers for bladder cancer management: present and future. American journal of clinical and experimental urology. 2014;2(1):1.

9. Veerakumarasivam A, Scott HE, Chin SF, Warren A, Wallard MJ, et al. High-resolution array-based comparative genomic hybridization of bladder cancers identifies mouse double minute 4 (MDM4) as an amplification target exclusive of MDM2 and TP53. Clinical Cancer Research. 2008; 14(9):25272534.

10. Lyss AP, Fagundes H, Corrigan P. Chemotherapy and Radiation For Dummies. John Wiley \& Sons; 2011 May 18.

11. Witjes JA, Compérat E, Cowan NC, De Santis M, Gakis $G$, et al. EAU guidelines on muscle-invasive and metastatic bladder cancer: summary of the 2013 guidelines. European urology. 2014;65(4):77892.

12. Ku, J.H. Bladder cancer. (1st Ed.), Academic Press, 2017, pp. 337-346.

13. Dolcet X, Llobet D, Pallares J, Matias-Guiu X. NF
$-\mathrm{kB}$ in development and progression of human cancer. Virchows archiv. 2005;446(5):475-82.

14. Sorriento D, Illario M, Finelli R, Iaccarino G. To $\mathrm{NF} \varkappa \mathrm{B}$ or not to NFxB: the dilemma on how to inhibit a cancer cell fate regulator. Translational medicine@UniSa. 2012 Sep;4:73.

15. Tong L, Yuan Y, Wu S. Therapeutic microRNAs targeting the NF-kappa B signaling circuits of cancers. Advanced drug delivery reviews. 2015 Jan 1;81:1-5.

16. Vasudevan KM, Gurumurthy S, Rangnekar VM. Suppression of PTEN expression by NF- $x \mathrm{~B}$ prevents apoptosis. Molecular and cellular biology. 2004;24(3):1007-21.

17. Irmler M, Thome M, Hahne M, Schneider P, Hofmann $\mathrm{K}$, et al. Inhibition of death receptor signals by cellular FLIP. Nature. 1997;388 (6638):190.

18. Wang CY, Mayo MW, Korneluk RG, Goeddel DV, Baldwin AS. NF- $x$ B antiapoptosis: induction of TRAF1 and TRAF2 and c-IAP1 and c-IAP2 to suppress caspase- 8 activation. Science. 1998;281 (5383):1680-3.

19. Wu CS, Pollack A, Czerniak B, Chyle V, Zagars GK, et al. Prognostic value of p53 in muscleinvasive bladder cancer treated with preoperative radiotherapy. Urology. 1996;47(3):305-10.

20. Osen I, Fosså SD, Majak B, Røtterud R, Berner A. Prognostic factors in muscle-invasive bladder cancer treated with radiotherapy: an immunohistochemical study. British journal of urology. 1998;81(6):862-9.

21. Fuessel S, Kunze D, Wirth MP. Bladder Cancer Biology. InBladder Cancer-From Basic Science to Robotic Surgery 2012. InTech.

22. Slaton JW, Benedict WF, Dinney CP. P53 in bladder cancer: mechanism of action, prognostic value, and target for therapy. Urology. 2001;57 (5):852-9.

23. Cote RJ, Esrig D \& Groshen S. p53 and treatment of bladder cancer. Nature. 1997:385:23-125.

24. Zamble DB, Jacks T, Lippard SJ. p53-Dependent and-independent responses to cisplatin in mouse testicular teratocarcinoma cells. Proceedings of the National Academy of Sciences. 1998;95(11):6163-8. 
25. Brown JM, Wouters BG. Apoptosis, p53, and tumour cell sensitivity to anticancer agents. Cancer research. 1999;59(7):1391-9.

26. Bartek J, Bartkova J, Lukas J. DNA damage signalling guards against activated oncogenes and tumour progression. Oncogene. 2007;26(56):7773.

27. Gurpinar E, Vousden KH. Hitting cancers' weak spots: vulnerabilities imposed by p53 mutation. Trends in cell biology. 2015;25(8):486-95.

28. Wang H, Cai Z, Yang F, Luo J, Satoh M, et al. Enhanced antitumour efficacy of integrin-targeted oncolytic adenovirus AxdAdB3-F/RGD on bladder cancer. Urology. 2014;83(2):508-e13.

29. Miyake H, Hara I, Gohji K, Yamanaka K, Arakawa $S$, et al. Enhancement of chemosensitivity in human bladder cancer cells by adenoviral-mediated p53 gene transfer. Anticancer research. 1998;18 (4C):3087-92.

30. Li X, Xiao S, Li Y, Zhang S. Clinical antiangiogenic effect of recombinant adenovirus-p53 combined with hyperthermia for advanced cancer. Chinese Journal of Cancer Research. 2013;25(6):749.

31. Pan JJ, Zhang SW, Chen CB, Xiao SW, Sun Y, et al. Effect of recombinant adenovirus-p53 combined with radiotherapy on long-term prognosis of advanced nasopharyngeal carcinoma. Journal of clinical oncology. 2008;27(5):799-804.

32. Chen GX, Zhang S, He XH, Liu SY, Ma C, et al. Clinical utility of recombinant adenoviral human p53 gene therapy: current perspectives. Onco'Targets and therapy. 2014;7:1901.

33. Kuball J, Wen SF, Leissner J, Atkins D, Meinhardt $\mathrm{P}$, et al. Successful adenovirus-mediated wild-type p53 gene transfer in patients with bladder cancer by intravesical vector instillation. Journal of Clinical Oncology. 2002;20(4):957-65.

34. Li Y, Li LJ, Wang LJ, Zhang Z, Gao N, et al. Selective intra-arterial infusion of rAd-p53 with chemotherapy for advanced oral cancer: a randomized clinical trial. BMC medicine. 2014;12 (1):16.

35. Schuler M, Herrmann R, De Greve JL, Stewart AK, Gatzemeier U, et al. Adenovirus-mediated wild-type p53 gene transfer in patients receiving chemotherapy for advanced non-small-cell lung cancer: results of a multicenter phase II study. Journal of Clinical Oncology. 2001;19(6):1750-8.
36. Pagliaro LC, Keyhani A, Williams D, Woods D, Liu B, et al. Repeated intravesical instillations of an adenoviral vector in patients with locally advanced bladder cancer: a phase I study of p53 gene therapy. Journal of clinical oncology. 2003;21 (12):2247-53.

37. Ang WX, Zhao Y, Kwang T, Wu C, Chen C, et al. Local immune stimulation by intravesical instillation of baculovirus to enable bladder cancer therapy. Scientific reports. 2016;6:27455.

38. Jacobsen NE, Gardner TA. Advances in Gene Therapy for Bladder Cancer. In Bladder Cancer 2009 (pp. 311-324). Humana Press.

39. Okegawa T, Pong RC, Li Y, Bergelson JM, Sagalowsky AI, et al. The mechanism of the growth-inhibitory effect of coxsackie and adenovirus receptor (CAR) on human bladder cancer: a functional analysis of car protein structure. Cancer research. 2001;61(17):6592-600.

40. Yang Y, Xu H, Shen J, Wu S, Xiao J, et al. RGDmodifided oncolytic adenovirus exhibited potent cytotoxic effect on CAR-negative bladder cancerinitiating cells. Cell death \& disease. 2015;6 (5):e1760.

41. Nagabhushan TL, Maneval DC, Benedict WF, Wen SF, Ihnat PM, et al. Enhancement of intravesical delivery with Syn3 potentiates interferon- $\alpha 2 \mathrm{~b}$ gene therapy for superficial bladder cancer. Cytokine \& growth factor reviews. 2007;18 (5-6):389-94.

42. Tazawa H, Kagawa S, Fujiwara T. p53 replacement therapy for cancer. InCurrent Strategies in Cancer Gene Therapy 2016 (pp. 1-15). Springer, Cham.

43. Araki D, Takayama K, Inoue M, Watanabe T, Kumon H, et al. Cell-penetrating D-isomer peptides of $\mathrm{p} 53 \mathrm{C}$-terminus: long-term inhibitory effect on the growth of bladder cancer. Urology. 2010;75(4):813-9.

44. Du Y, Wang L, Wang W, Guo T, Zhang M, et al. Novel Application of Cell Penetrating R11 Peptide for Diagnosis of Bladder Cancer. Journal of biomedical nanotechnology. 2018;14(1):161-7.

45. Laptenko O, Tong DR, Manfredi J, Prives C. The tail that wags the dog: how the disordered Cterminal domain controls the transcriptional activities of the p53 tumour-suppressor protein. Trends in biochemical sciences. 2016;41(12):1022- 
34.

46. Ahn J, Prives C. The C-terminus of p53: the more you learn the less you know. Nature Structural and Molecular Biology. 2001;8(9):730.

47. Surget $\mathrm{S}$, Khoury MP, Bourdon JC. Uncovering the role of p53 splice variants in human malignancy: a clinical perspective. OncoTargets and therapy. 2014;7:57.

48. Takenobu T, Tomizawa K, Matsushita M, Li ST, Moriwaki A, et al. Development of p53 Protein Transduction Therapy Using Membrane-permeable Peptides and the Application to Oral Cancer Cells 1. Molecular cancer therapeutics. 2002;1(12):10439 .

49. Han X, Bushweller JH, Cafiso DS, Tamm LK. Membrane structure and fusion-triggering conformational change of the fusion domain from influenza hemagglutinin. Nature Structural and Molecular Biology. 2001 Aug;8(8):715.

50. Skehel JJ, Cross K, Steinhauer D, Wiley DC. Influenza fusion peptides. Biochem Soc Trans. 2001;29:623-626.

51. Min KA, Maharjan P, Ham S, Shin MC. Proapoptotic peptides-based cancer therapies: challenges and strategies to enhance therapeutic efficacy. Archives of pharmacal research. 2018;41 (6):594-616.

52. Karni-Schmidt O, Lokshin M, Prives C. The roles of MDM2 and MDMX in cancer. Annual Review of Pathology: Mechanisms of Disease. 2016;11:617 $-44$.

53. Wade M, Wang YV, Wahl GM. The p53 orchestra: Mdm2 and Mdmx set the tone. Trends in cell biology. 2010;20(5):299-309.

54. Gilkes DM, Pan Y, Coppola D, Yeatman T, Reuther GW, et al. Regulation of MDMX expression by mitogenic signaling. Molecular and cellular biology. 2008;28(6):1999-2010.

55. Riemenschneider MJ, Büschges R, Wolter M, Reifenberger J, Boström J, et al. Amplification and overexpression of the MDM4 (MDMX) gene from $1 \mathrm{q} 32$ in a subset of malignant gliomas without TP53 mutation or MDM2 amplification. Cancer research. 1999;59(24):6091-6.

56. Marine JC, Jochemsen AG. MDMX (MDM4), a promising target for $\mathrm{p} 53$ reactivation therapy and beyond. Cold Spring Harbor perspectives in medicine. 2016;6(7):a026237.

57. Alt JR, Greiner TC, Cleveland JL, Eischen CM. Mdm2 haplo-insufficiency profoundly inhibits Mycinduced lymphomagenesis. The EMBO journal. 2003;22(6):1442-50.

58. Nag S, Zhang X, Srivenugopal KS, Wang MH, Wang W, et al. Targeting MDM2-p53 interaction for cancer therapy: are we there yet? Current medicinal chemistry. 2014;21(5):553-74.

59. Huang Q, Chen L, Yang L, Xie X, Gan L, Cleveland JL, Chen J. MDMX acidic domain inhibits p53 DNA binding in vivo and regulates tumorigenesis. Proceedings of the National Academy of Sciences. 2018 Apr 10;115(15):E336877.

60. Hu B, Gilkes DM, Chen J. Efficient p53 activation and apoptosis by simultaneous disruption of binding to MDM2 and MDMX. Cancer Research. 2007;67(18):8810-7.

61. Shangary S, Qin D, McEachern D, Liu M, Miller RS, et al. Temporal activation of p53 by a specific MDM2 inhibitor is selectively toxic to tumours and leads to complete tumour growth inhibition. Proceedings of the National Academy of Sciences. 2008;105(10):3933-8.

62. Lu Y, Nikolovska-Coleska Z, Fang X, Gao W, Shangary $S$, et al. Discovery of a nanomolar inhibitor of the human murine double minute 2 (MDM2) - p53 interaction through an integrated, virtual database screening strategy. Journal of medicinal chemistry. 2006;49(13):3759-62.

63. Boyarskikh U, Pintus S, Mandrik N, Stelmashenko D, Kiselev I, et al. Computational master-regulator search reveals mTOR and PI3K pathways responsible for low sensitivity of NCI-H292 and A427 lung cancer cell lines to cytotoxic action of p53 activator Nutlin-3. BMC medical genomics. 2018;11(1):12.

64. Wade M, Rodewald LW, Espinosa JM, Wahl GM. BH3 activation blocks Hdmx suppression of apoptosis and cooperates with Nutlin to induce cell death. Cell Cycle. 2008;7(13):1973-82.

65. Hu B, Gilkes DM, Farooqi B, Sebti SM, Chen J. MDMX overexpression prevents p53 activation by the MDM2 inhibitor Nutlin. Journal of Biological Chemistry. 2006;281(44):33030-5.

66. Laurie NA, Donovan SL, Shih CS, Zhang J, Mills 
$\mathrm{N}$, et al. Inactivation of the p53 pathway in retinoblastoma. Nature. 2006;444(7115):61.

67. Tan BX, Khoo KH, Lim TM, Lane DP. High

Mdm4 levels suppress p53 activity and enhance its half-life in acute myeloid leukaemia. Oncotarget. 2014;5(4):933. 